ORIGINAL RESEARCH

\author{
T.G. Abud \\ A. Nguyen \\ J.P. Saint-Maurice \\ D.G. Abud \\ D. Bresson \\ L. Chiumarulo \\ E. Enesi \\ E. Houdart
}

\title{
The Use of Onyx in Different Types of Intracranial Dural Arteriovenous Fistula
}

BACKGROUND AND PURPOSE: Recently some series have been published about the use of Onyx for the treatment of DAFVs with satisfactory results. Our aim was to describe the treatment of different types of intracranial DAVFs with transcatheter injection of Onyx through an arterial approach.

MATERIALS AND METHODS: At the Department of Interventional Neuroradiology, Hospital Lariboisière Paris, between January 2005 and January 2010, we treated 44 DAVFs in 42 patients. All patients were initially treated by arterial injection of Onyx. The average patient age was 56 years (range, 27-86 years), and there were 17 women and 25 men treated.

RESULTS: A total of 58 arterial pedicles were catheterized, with the middle meningeal artery representing the most common site $(n=38)$. The average time of injection was 30 minutes (range, 15-60 minutes), and the average amount of Onyx was $2.5 \mathrm{~mL}$ (range, $0.6-6.5 \mathrm{~mL}$ ). Of the 20 fistulas with direct venous drainage into a dural sinus (types I and II), we achieved the preservation of the sinus in 7 patients. Of the 44 fistulas embolized, 8 required a second embolization treatment and 1 fistula required a third treatment. In 9 cases, a complementary treatment was performed via transvenous embolization with coils and/or open surgery. Early complications were observed in 6 patients: Four had nerve injury (facial palsy, $n=2$, and neuralgia, $n=2$ ), and 2 had complications related to extension of venous thrombosis postembolization. All 6 patients had partial or complete resolution of these symptoms.

concLusions: The treatment of DAVFs by intracranial arterial injection of Onyx is safe, and, in most cases, results in the occlusion of the arterial venous shunt. In DAVFs with direct sinus drainage, sinus preservation was only possible in 7 of 20 patients (35\%).

ABBREVIATIONS CVR $=$ cortical venous reflux; DAVF = dural arteriovenous fistula; DMSO = dimethyl-sulfoxide; Onyx LES = Onyx Liquid Embolic System

$\mathbf{T}$ reatment of intracranial DAVFs with direct cortical venous drainage or with reflux into the cortical veins is possible by surgical or endovascular arterial injections of Onyx (ev3, Irvine, California) or cyanoacrylate. ${ }^{1}$

Recent articles have demonstrated that the endovascular technique by using Onyx has some advantages over cyanoacrylate, including the following: greater control of the embolic agent during injection, injection time, and overall high cure rates with few complications. ${ }^{2-6}$

In contrast to DAVFs with direct cortical venous drainage and reflux into cortical veins, fistulas with direct drainage into the venous sinuses are often treated with a transvenous approach, particularly for lateral or cavernous sinus DAVFs. ${ }^{7,8}$ The cavernous DAVFs rarely have favorable arterial access, but the fistulas located in the lateral sinus often have arterial pedicles amenable to selective catheterization and adequate injection of Onyx.

We started by using Onyx for the treatment of intracranial DAVFs in 2005 on the basis of these preliminary results and our experience in treating this pathology. In our series, we have included the subset of fistulas with direct venous sinus drainage, with the secondary treatment goal of preserving ve-

Received December 27, 2010; accepted after revision April 11, 2011.

From the Service de Neuroradiologie Diagnostique et Interventionnelle (T.G.A., A.N., J.P.S.-M., D.G.A., L.C., E.E., E.H.), Hopital Lariboisière, Paris, France; and Service de Neurochirurgie (D.B.), Hopital Lariboisière, Paris, France.

Please address correspondence to Emmanuel Houdart, MD, Service de Neuroradiologie Diagnostique et Interventionnelle, Hopital Lariboisière, 2 rue Ambroise Paré, 75010 Paris, France; e-mail: emmanuel.houdart@|rb.aphp.fr

http://dx.doi.org/10.3174/ajnr.A2702 nous sinus patency and function. The aim of the study was to present our results with the endovascular treatment of intracranial DAVFs by using Onyx.

\section{Materials and Methods}

\section{Patients and Techniques}

Between January 2005 and January 2010, the Department of Interventional Neuroradiology at the Lariboisière Hospital in Paris performed 46 endovascular procedures for the treatment of 44 intracranial DAVFs diagnosed in 42 patients. All patients were initially treated by arterial injection of Onyx LES. The mean age of the patients was 56 years (range, 27-86 years), and there were 25 women and 28 men.

All procedures were performed by using the following fluoroscopic equipment with DSA: a biplane flat-detector Axiom Artis dBA (Siemens, Erlangen, Germany) and a single-plane Advantx LCV (GE Healthcare, Milwaukee, Wisconsin).

\section{Clinical Presentation}

The patients presented with a wide spectrum of symptoms. The initial clinical presentation was most frequently pulsatile tinnitus $(n=16)$, followed by hemorrhage $(n=6)$ and headache $(n=5)$ as shown in Table 1.

\section{DSA and DAVF Classification}

DSA was performed in all cases to confirm the diagnosis and angiographic classification and to assist in the treatment planning.

The DAVFs were classified according to the system of Lariboisière. ${ }^{9}$ Angiography was performed with the patient under local anesthesia via a femoral artery access route with the introduction of a 


\section{Table 1: Clinical presentation}

\begin{tabular}{lc}
\hline & No. of Patients \\
\hline Pulsatile tinnitus & 16 \\
Hemorrhage & 6 \\
Headache & 5 \\
Nonhemorrhagic neurologic deficit & 4 \\
Vasculonervous conflict & 4 \\
Dementia & 3 \\
Seizures & 2 \\
Asymptomatic & 2 \\
Total & 42
\end{tabular}

5F sheath. We performed selective catheterizations of the common, internal, and external carotid and vertebral arteries. The angiographic images were acquired in the anteroposterior and lateral projections. When necessary, additional oblique series were performed.

\section{Treatment}

All treatment procedures were performed with the patient under general anesthesia. After the groin was prepped and draped, femoral artery puncture was performed and a $6 \mathrm{~F}$ sheath was introduced. There was a preference for access of the right femoral artery. An intravenous bolus of $3000 \mathrm{IU}$ of heparin was given at the beginning of each procedure. A $6 \mathrm{~F}$ guiding catheter was then positioned within the proximal portion of the external carotid artery and perfused with $3 \mathrm{mg} / \mathrm{L}$ of nimodipine in normal saline.

The identification of optimal working projections is one of the most important steps of the DAVF treatment. The projections are needed to differentiate the venous collection system from the feeding arterial branches. In addition, the proper visualization of the venous sinus and cortical draining vein systems is critical.

The selective catheterization was performed by using microcatheters compatible with the Onyx LES: Sonic 1.5F (Balt, Montmorency, France), Echelon 10 and 14 (ev3), Marathon 14 (ev3), and UltraFlow (ev3). The microcatheters were guided into position by using a variety of microwires: Mirage 008 (ev3), Transend-14 (Boston Scientific, Natick, Massachusetts), Whisper (Abbott Laboratories, Rockville, Maryland), and Synchro-10 (Boston Scientific).

The selective microcatheterization was performed under direct visualization using digital roadmap images. After positioning of the catheter tip, a series of images was acquired with contrast injection to analyze the anatomic structure and dynamic flow behavior of the fistula.

After the image analysis, the Onyx LES was prepared according to the instructions of the manufacturer: syringes of DMSO and Onyx copolymer (Onyx 18 or 34) were loaded. The dead-space volume within the microcatheter was first filled with DMSO and subsequently with Onyx by using a slow rate of injection according to recommendations of the manufacturer. The Onyx was injected into the fistula under constant fluoroscopic visualization and was stopped when consistent reflux was noted. Subsequent injections were re-initiated after waiting 1-2 minutes. Control angiograms were obtained during the embolization treatment, as necessary, to evaluate the degree of fistula occlusion.

The higher attenuation Onyx 34 embolic agent was used in 6 cases in which the fistula was observed to result in a high-output shunt. The increased copolymer attenuation allowed improved cohesion of the embolic cast and helped to minimize distal migration. The amount of Onyx 34 injected varied from 0.2 to $0.6 \mathrm{~mL}$. The Onyx 34, used in conjunction with Onyx 18, resulted in very favorable cure rates. The
Table 2: DAVF location and type

\begin{tabular}{|c|c|c|c|c|c|c|c|c|}
\hline \multirow[b]{2}{*}{ Location } & \multicolumn{8}{|c|}{ DAVF Type } \\
\hline & No. & I & II a & II b & $\mathrm{II} a+\mathrm{b}$ & III & IV & V \\
\hline Sigmoid sinus & 15 & 5 & 3 & 4 & 3 & 0 & 0 & 0 \\
\hline Transverse sinus & 5 & 0 & 0 & 3 & 0 & 2 & 0 & 0 \\
\hline Superior sagittal sinus & 10 & 0 & 0 & 1 & 0 & 8 & 1 & 0 \\
\hline Anterior fossa & 6 & 0 & 0 & 1 & 0 & 1 & 4 & 0 \\
\hline Tentorium & 5 & 0 & 0 & 0 & 0 & 4 & 0 & 1 \\
\hline Other & 3 & 0 & 0 & 2 & 0 & 0 & 0 & 0 \\
\hline Total & 44 & 5 & 4 & 11 & 3 & 15 & 5 & 1 \\
\hline
\end{tabular}

decision as to which concentration of Onyx to use was subjective and was based on the feeling of the flow velocity of the shunt and the risk of venous migration.

In 2 patients, a multimodal embolization strategy was necessary: Transvenous coil embolization was augmented with transvenous injection of Onyx within the venous drainage system with a goal of complete occlusion.

At the conclusion of the treatment session, we performed control angiographic contrast injections in the internal carotid, external carotid, and vertebral arteries to evaluate the embolic result and fistula occlusion. In the fistulas with direct drainage into the dural sinuses (types I and II), we evaluated the preservation and patency of the venous sinus.

\section{Follow-Up Protocol}

All patients were admitted to the hospital and clinically observed after the procedure. Clinical evaluation was performed between 1 and 6 months after the embolization treatment. According to our protocol, all patients must undergo a single control angiogram 6 months after the procedure. If no recurrence is noted, the patient is considered cured.

\section{Results}

Most DAVFs treated had cortical venous drainage or cortical venous reflux (36 of 44), as illustrated by Table 2 .

A majority of patients with DAVFs (27 of 44) were cured with a single microcatheter embolization as indicated in Table 3. An additional 8 fistulas required a second microcatheterization for complete occlusion. One patient required a third microcatheterization during the treatment session for an embolic cure.

After treatment with transarterial Onyx injection, a significant residual shunt was observed in 9 patients. Of these 9 , we completed the treatment by transvenous access and embolization with coil placement and Onyx embolization in 5 ( 4 within the same treatment session). Traditional surgical intervention was performed in the remaining 4 patients to complete the occlusion of the arteriovenous shunt.

A total of 58 arterial pedicles were catheterized (Table 4). The middle meningeal artery was the most common artery catheterized ( $n=38)$, followed by the occipital artery $(n=11)$ and the ophthalmic artery $(n=6)$.

Four patients embolized in a single session showed a minimal residual shunt on immediate posttreatment angiography, which completely occluded on follow-up angiographic control imaging.

The average Onyx injection time was 30 minutes (range, 15-60 minutes), and the amount of Onyx injected per pedicle was $2.5 \mathrm{~mL}$ on average (range, $0.6-6.5 \mathrm{~mL}$ ). 


\begin{tabular}{|c|c|c|c|c|c|c|}
\hline Location & No. & $\begin{array}{l}\text { Cured with } \\
1 \text { Onyx } \\
\text { Injection }\end{array}$ & $\begin{array}{l}\text { Cured with } \\
\geq 2 \text { Onyx } \\
\text { Injections }\end{array}$ & $\begin{array}{c}\text { Failure to } \\
\text { Occlude with } \\
\text { Transarterial Onyx }\end{array}$ & $\begin{array}{l}\text { Transvenous } \\
\text { Embolization }\end{array}$ & $\begin{array}{c}\text { Surgical } \\
\text { Treatment }\end{array}$ \\
\hline Sigmoid sinus & 15 & 9 & 3 & 3 & 2 & 1 \\
\hline Transverse sinus & 5 & 4 & 1 & 0 & 0 & 0 \\
\hline Superior sagittal sinus & 10 & 8 & 2 & 1 & 0 & 1 \\
\hline Anterior fossa & 6 & 4 & 1 & 1 & 0 & 1 \\
\hline Tentorium & 5 & 2 & 1 & 2 & 1 & 1 \\
\hline Other & 3 & 0 & 1 & 2 & 2 & 0 \\
\hline Total & 44 & 27 & 9 & 9 & 5 & 4 \\
\hline
\end{tabular}

\begin{tabular}{|c|c|c|c|c|c|c|}
\hline Location & $\begin{array}{c}\text { No. of } \\
\text { Fistulas }\end{array}$ & $\begin{array}{c}\text { Middle Meningeal } \\
\text { Artery }\end{array}$ & $\begin{array}{l}\text { Ophthalmic } \\
\text { Artery }\end{array}$ & $\begin{array}{c}\text { Occipital } \\
\text { Artery }\end{array}$ & $\begin{array}{l}\text { Other } \\
\text { Artery }\end{array}$ & Total \\
\hline Sigmoid sinus & 15 & 15 & 0 & 4 & 0 & 19 \\
\hline Transverse sinus & 5 & 5 & 0 & 1 & 0 & 6 \\
\hline Superior sagittal sinus & 10 & 10 & 0 & 2 & 1 & 13 \\
\hline Anterior fossa & 6 & 1 & 6 & 0 & 0 & 7 \\
\hline Tentorium & 5 & 5 & 0 & 1 & 2 & 8 \\
\hline Other & 3 & 2 & 0 & 3 & 0 & 5 \\
\hline Total & 44 & 38 & 6 & 11 & 3 & 58 \\
\hline
\end{tabular}

\begin{tabular}{lccr}
\hline \multicolumn{4}{l}{ Table 5: Sinus preservation in DAVF types I and II } \\
\hline Type & Total & Yes & No \\
\hline I & 5 & 3 & 2 \\
II a & 3 & 1 & 2 \\
II b & 9 & 2 & 7 \\
II a + b & 3 & 1 & 2 \\
Total & 20 & 7 & 13 \\
\hline
\end{tabular}

\begin{tabular}{lcccc}
\hline \multicolumn{5}{l}{ Table 6: Cure rates } \\
\hline Location & Type & Onyx 34 & Onyx 18 & Cured $^{\text {a }}$ \\
\hline Sigmoid sinus & II a + b & 0.3 & 2.5 & Yes \\
Torcula & II b & 0.5 & 3.0 & No \\
Transverse sinus & II b & 0.4 & 2.4 & Yes \\
Sigmoid sinus & II a & 0.4 & 2.6 & Yes \\
Sagittal sinus & III & 0.4 & 4.0 & Yes \\
Tentorium & III & 0.6 & 2.5 & Yes \\
\hline
\end{tabular}

a Cured by 1 procedure.

\begin{tabular}{lc}
\hline Table 7: Complications & \\
\hline Complication & No. of Patients \\
\hline Venous thrombosis & 2 \\
Facial nerve paresis & 2 \\
Trigeminal nerve pain & 2 \\
Total & 6 \\
\hline
\end{tabular}

\section{Sinus Preservation}

In the 20 fistulas with drainage into the venous sinus (types I and II) treated, we preserved the venous sinus in 7 instances (Table 5). In the other 13 fistulas, the sinus could not be preserved and the flow of the brain after the procedures was accomplished through collateral drainage (contralateral sinus or collateral flow through the cortical veins).

\section{Complications}

We observed early complications related to cranial neuropathies in 4 patients (Tables 6 and 7): Two had facial paresis and 2 had neuropathic pain in the distribution of the trigeminal nerve. These symptoms gradually resolved during the clinical follow-up period. Another early complication observed was the development of venous thrombosis in 2 patients. One patient had recurrent seizures and another had headache. The seizure and the headache could be controlled with medical treatment. There were no complications resulting from the selective microcatheterization or withdrawal of the microcatheter.

\section{Angiographic Follow-Up}

All 40 patients cured by embolization alone underwent a single angiography 6 months after the procedure, showing a stable result, meaning no recurrence. In the 4 patients who underwent complementary open surgery, a control angiogram was obtained at 3 months, which also confirmed stable exclusion of the DAVFs.

\section{Discussion}

Intracranial DAVFs are uncommon lesions, constituting 15\% of all cerebrovascular malformations. From the standpoint of pathology, the feeding arteries are meningeal branches, the shunt is located in the intracranial dura mater, and the intracranial drainage is directed to the dural venous sinuses or cortical veins. ${ }^{9}$

The symptoms and prognosis are related to the type of venous return and may be characterized by the Lariboisière classification: drainage into a venous sinus without cortical reflux (types I and IIa), into a venous sinus with cortical reflux (type IIb), into a venous sinus with cortical reflux (type IIb), into a cortical vein (types III and IV) or with spinal medullary venous drainage (type $\mathrm{V}$ ). The fistulas with cortical venous involvement carry a higher bleeding risk. ${ }^{9}$

DAVFs with retrograde flow into cortical veins exhibit a much higher incidence of hemorrhage or venous infarction. The annual mortality rate for lesions with cortical venous reflux may be as high as $10.4 \%$, whereas the annual risk for hemorrhage or nonhemorrhagic neurologic deficits during 

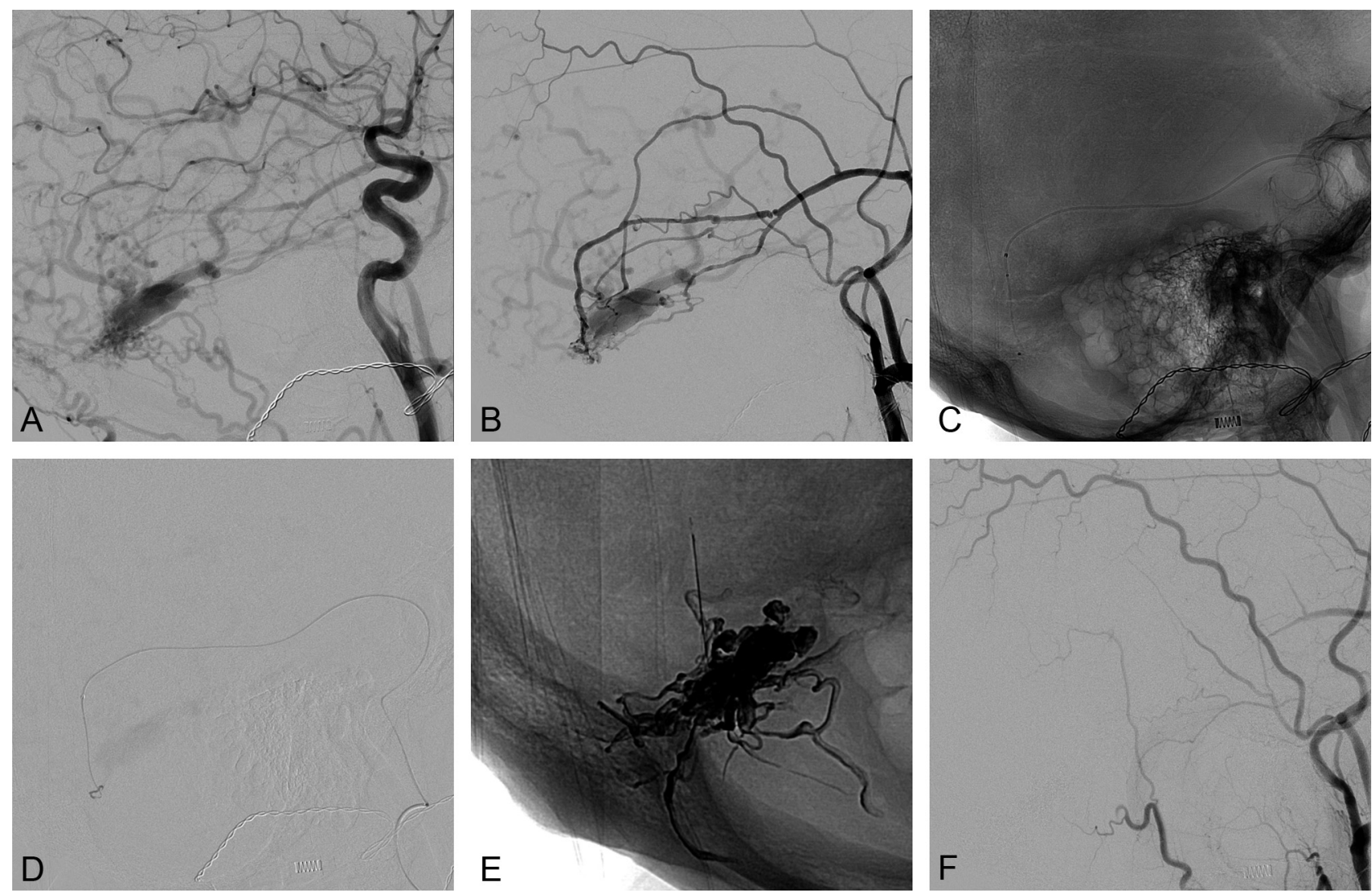

Fig 1. $A$ and $B$, Anterior and lateral external carotid artery injections in early phases show a sigmoid DAVF type III. $C$ and $D, A$ microcatheter compatible with Onyx was positioned in the middle meningeal artery. $E$, Cast of Onyx. F, Final controls by external carotid artery injection show the absence of a residual fistula.

follow-up is $8.1 \%$ and $6.9 \%$, respectively, resulting in an annual event rate of $15 \%$. $^{9}$

DAVFs with direct drainage into a cortical vein or with CVR require treatment aimed at a complete and definitive fistula closure because they have a high risk of hemorrhage and venous infarction. The treatment may also be indicated for fistulas seen as benign (no CVR) when the patient cannot tolerate the symptoms, usually pulsatile tinnitus from the high flow shunt or headache related to intracranial hypertension. ${ }^{9}$

The definitive treatment of DAVFs requires the occlusion of the arteriovenous shunt. The treatment can be performed by conventional open neurosurgery or endovascular embolization. Traditionally, endovascular treatment has focused on occlusion of the venous sinus drainage system by venous access and transvenous embolization, typically with embolic coils. In cases in which venous access was difficult or impossible, an arterial approach was used and embolic particles or glue was injected into the fistula, frequently with incomplete results.

In the early 21 st century, the use of an ethylene-vinyl alcohol copolymer, Onyx LES, in arteriovenous malformations changed the concept of embolization. Especially for the treatment of DAVFs, Onyx embolization became a simpler and less aggressive alternative to traditional surgery. Onyx has been particularly effective in treating DAVFs with direct drainage into cortical veins. Since its inception, Onyx has been enthusiastically adopted and trialed in many types of fistulas with encouraging preliminary results. ${ }^{5,10}$

For many years, the transarterial approach for DAVF em- bolization has been a last resort, reserved for cases when venous embolization was not feasible or conventional surgery was not possible. The embolic materials available at the time, cyanoacrylate glues and particles, were ill-suited to the pathology and had poor efficacy in curing the fistulas. With the introduction of the Onyx copolymer material and its novel physical properties, the transarterial approach has had a renaissance. Onyx is a gelling solution, more specifically, a copolymer suspended in a solvent. ${ }^{11}$ On injection into the artery, the volatile DMSO solvent disperses in arterial blood flow and the copolymer is deposited onto the arterial walls. In practice, the progress of the embolus formation can be controlled. Manipulation of the flow of embolic solution, by interrupting and re-initiating the injection, can redirect the path of the forming embolus. ${ }^{11}$ This increased control made it possible to deal with DAVFs with multiple arterial supplies, allowing the Onyx to penetrate into the afferent arteries well before the draining veins are affected. ${ }^{12}$

In 2006, Rezende et $\mathrm{al}^{6}$ reported the first case of a DAVF occluded with Onyx in a patient with a lesser sphenoid wing fistula with direct cortical venous drainage. Subsequently, other case reports and case series were published..$^{2-5}$

We started by using Onyx for the treatment of intracranial DAVFs in 2005 based on the promising preliminary results and our experience in treating this pathology. Our series included a wide spectrum of clinical presentations, DAVF subtypes, and lesion locations. In particular, we included fistulas with sinus drainage, with the goal of preserving the sinus patency and function. 

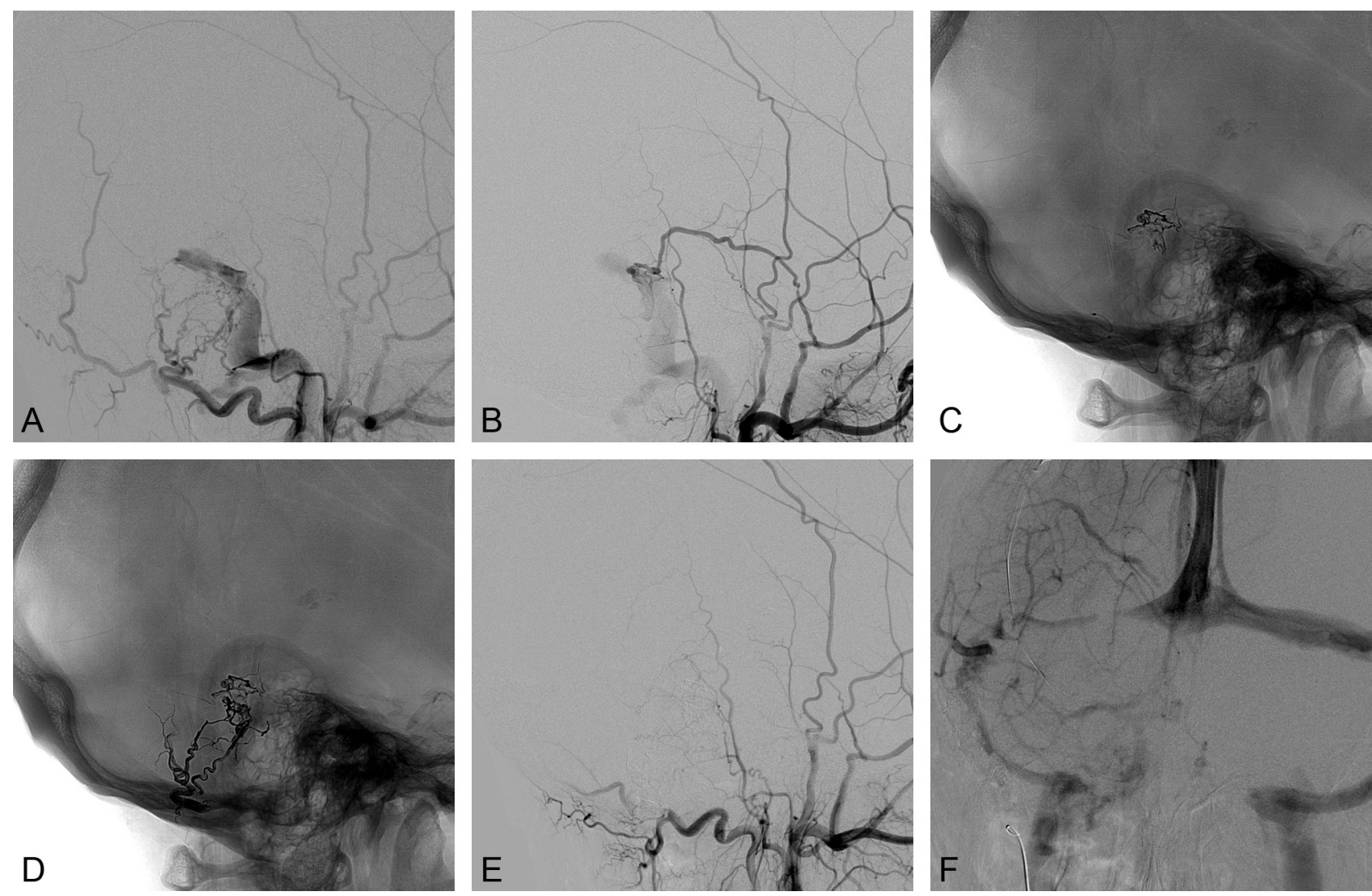

Fig 2. $A$ and $B$, Lateral external carotid artery injection in the early phase shows a sigmoid DAVF type I. Cast of Onyx after 2 Onyx injections: the first by the middle meningeal artery $(C)$ and the second by a branch of occipital artery $(D)$. E and $F$, Final controls of the external carotid and internal carotid arteries early and late phases show the absence of a residual fistula and satisfactory sigmoid sinus preservation.

In 36 of 44 procedures ( $81 \%$ ), we obtained a cure with just a single procedure (Fig 1). Of the remaining 8 fistulas, 3 resulted in an angiographic cure with a second embolization session and 1 required a third endovascular treatment. In a minority of lesions (5 of 44), both transarterial and transvenous approaches were used to effect a cure. A remaining 4 patients did require additional open neurosurgical intervention for lesion eradication. Overall, by using a treatment algorithm based on arterial injection of Onyx, complemented by transvenous embolization, we embolized and cured 40 of the $44(91 \%)$ fistulas treated. Better anatomic outcome was related to the presence of direct meningeal artery feeders, whereas embolization through transosseous feeders was less effective.

Complications were observed in 6 patients: Four developed a cranial nerve injury ( 2 with facial palsy and 2 with trigeminal neuralgia), and 2 patients had extension of a venous thrombosis. All cases showed partial or complete regression of symptoms at the last clinical follow-up.

All the cranial nerve injuries resulted in exaggerated reflux of Onyx in branches of the middle meningeal artery. One patient presented with partial (facial nerve palsy) regression of symptoms, and 3 patients were asymptomatic at the last clinical follow-up. The patients who had venous thrombosis were treated medically and did not present with seizures or new symptoms. We believe that the slowing of flow within the venous sinuses and cortical veins is associated with thrombosis.

In 2008, Cognard et $\mathrm{al}^{5}$ presented a series of 30 patients with DAVFs; a majority of the fistulas $(n=20)$ had direct cortical venous drainage. A complete angiographic cure was achieved in 23 of 25 (92\%) patients who were not previously treated. No lesion recurrence was noted on follow-up imaging. In 20 patients, only 1 treatment session was required. One patient with a tentorial DAVF developed ophthalmoplegia and facial pain after partial embolization due to Onyx reflux in the foramen spinosum. The fistula rebled 2 years later. Another patient with a tentorial DAVF had a cerebellar syndrome and postembolization hemorrhage resulting from extensive thrombosis of the draining vein. ${ }^{5}$

Nogueira et al $(2008)^{13}$ reported a $91.7 \%$ cure rate in a series of 12 patients with no significant morbidity or mortality. Ten lesions had direct cortical venous drainage. One fistula recanalized in the $9(11 \%)$ patients followed up angiographically. Trivelato et $\mathrm{al}^{2}$ published a selected series of 9 patients with DAVFs and direct cortical venous drainage; they noted a high rate of complete occlusion with no complications.

In our series, we treated a large proportion of dural fistulas with drainage into a dural sinus (Lariboisière types I and II) and were able to preserve the venous sinus in 7 of the $20 \mathrm{pa}-$ tients. Regarding the treatment algorithm for these benign fistulas, we initiated treatment with arterial injections of Onyx in an attempt to preserve the venous sinus (Fig 2). If it was not possible to exclude the fistula while preserving the sinus, we proceeded to occlude the fistula and sacrificed the patency of the sinus (Fig 3). All the fistulas considered for treatment were draining to hemodynamically excluded sinuses; then, though 

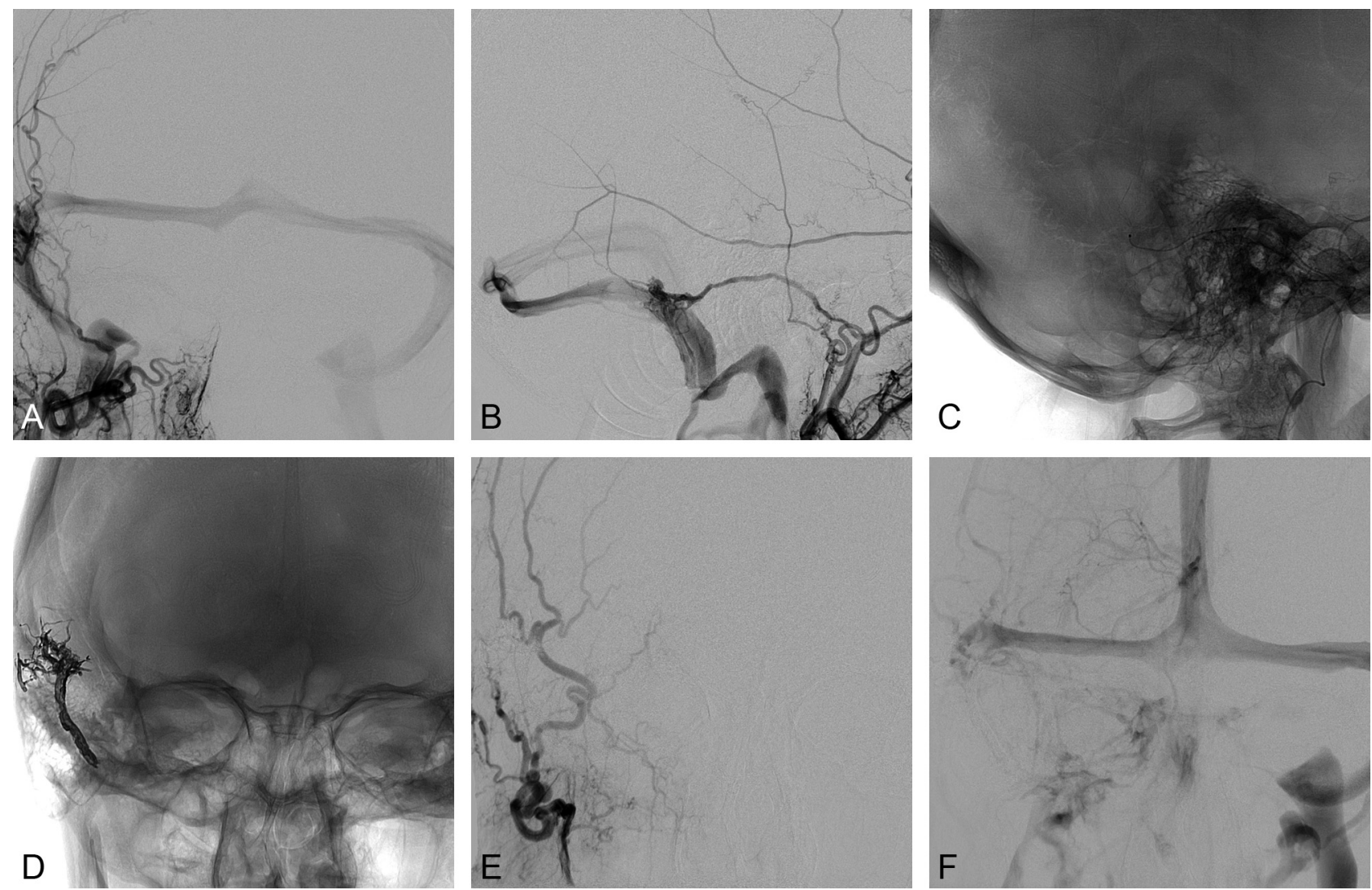

Fig 3. $A$ and $B$, Anterior and lateral external artery injections in the early phases show a sigmoid DAVF type $\|$ a. $C$, A microcatheter compatible with Onyx is positioned in the middle meningeal artery. $D$, Cast of Onyx filling the sigmoid sinus. $E$ and $F$, Final controls of external carotid and internal carotid artery early and late phases show the absence of residual fistula and satisfactory sigmoid sinus exclusion.

we wanted primarily to preserve them, exclusion of the fistula with the sinus was also considered a satisfactory result.

The type I DAVF of the lateral sinus does not represent a neurologic risk. The treatment goal is removal of the clinical symptom: the pulsatile tinnitus. Consequently, the indication for treatment depends exclusively on functional considerations. Some patients can tolerate the clinical manifestations once they have been reassured about the benign nature of their lesion. For these patients, there is no indication to treat. However, in other patients, the symptoms are not well-tolerated and can manifest as sleep disorders, mood disturbances, irritability, or even depression. These patients often clinically present with daily consumption of sleeping pills and tranquilizers. The treatment in these cases is entirely appropriate. It is critical to emphasize that the endovascular treatment of DAVFs, in much the same way as the surgical treatment, involves significant risks to neurologic function and can have life-threatening consequences.

For the type IIa DAVF of the lateral sinus, the presenting symptom is usually still pulsatile tinnitus, which can be isolated or associated with signs of intracranial hypertension. Head CT and MR imaging findings of the brain are generally normal, even with respect to the ventricle size. It is important to be cognizant of this diagnosis on the differential for intracranial hypertension because lumbar puncture is contraindicated. In our own institution, we had a case of a lumbar puncture resulting in a serious clinical deterioration leading to the patient's death.
Fistulas of the anterior cranial fossa usually have direct drainage into cortical veins and present as frontal hemorrhages. These fistulas differ from other subtypes because the arterial supply is fed preferentially by meningeal branches of the ophthalmic artery. This can present technical challenges to selective navigation of the microcatheter, and we must respect the anatomic limitations to avoid complications. ${ }^{14-16}$

Another distinguishing feature of our study was the use of Onyx 34 in a subset of DAVF treatments. This higher attenuation version of the Onyx copolymer was used in 6 patients to mitigate distal migration of the embolic agent in fistulas that contained a high-flow shunt. The amount injected varied from 0.2 to $0.6 \mathrm{~mL}$. In 5 of the 6 cases where it was used, we achieved an angiographic cure. We believe that Onyx 34 helps prevent the premature migration of the embolic agent in the beginning of the procedure and allows the formation of a better Onyx cast. Its use may also reduce the need for additional treatments and catheterizations.

Serious treatment-related complications are not frequent and occur almost exclusively in DAVFs with leptomeningeal drainage. These cerebral complications are due to hemorrhage, thought to be a consequence of an extension of thrombosis from the site of the fistula into the leptomeningeal veins. Their overall frequency in the literature is approximately $5 \%$ by an arterial or venous approach. As a prophylactic measure, anticoagulant therapy is often instituted after embolization. ${ }^{1-3,5}$ 


\section{Conclusions}

The treatment of DAVFs by using Onyx by an arterial approach is effective and safe and allows the complete occlusion of the arterial venous shunt in a single session in most cases. In the subset of DAVFs with direct drainage into a dural sinus, the arterial approach can be used with Onyx injection and the venous sinus can be preserved.

\section{References}

1. van Dijk JM, terBrugge KG, Willinsky RA, et al. Clinical course of cranial dural arteriovenous fistulas with long-term persistent cortical venous reflux. Stroke 2002;33:1233-36

2. Trivelato FP, Abud DG, Ulhoa AC, et al. Dural arteriovenous fistulas with direct cortical venous drainage treated with Onyx: a case series. Arq Neuropsiquiatr 2010;68:613-18

3. Rossitti S. Transarterial embolization of intracranial dural arteriovenous fistulas with direct cortical venous drainage using ethylene vinyl alcohol copolymer (Onyx). Klin Neuroradiol 2009;19:122-28

4. Macdonald JH, Millar JS, Barker CS. Endovascular treatment of cranial dural arteriovenous fistulae: a single-centre, 14-year experience and the impact of Onyx on local practise. Neuroradiology 2010;52:387-95. Epub 2009 Nov 4

5. Cognard C, Januel AC, Silva NA Jr, et al. Endovascular treatment of intracranial dural arteriovenous fistulas with cortical venous drainage: new management using Onyx. AJNR Am J Neuroradiol 2008;29:235-41

6. Rezende MT, Piotin M, Mounayer C, et al. Dural arteriovenous fistula of the lesser sphenoid wing region treated with Onyx: technical note. Neuroradiology $2006 ; 48130-34$
7. Gobin YP, Houdart E, Rogopoulos A, et al. Percutaneous transvenous embolization through the thrombosed sinus in transverse sinus dural fistula. AJNR Am J Neuroradiol 1993;14:1102-90

8. Theron J, Clay C, Djindjian R. Angiographic study and embolization of a paracavernous dural arteriovenous fistula of an unusual anatomical type [in French]. Ann Radiol (Paris) 1975;18:729-46

9. Cognard C, Gobin YP, Pierot L, et al. Cerebral dural arteriovenous fistulas: clinical and angiographic correlation with a revised classification of venous drainage. Radiology 1995;194:671-80

10. Toulgoat F, Mounayer C, Tulio Salles Rezende M, et al. Transarterial embolisation of intracranial dural arteriovenous malformations with ethylene vinyl alcohol copolymer (Onyx18) [in French]. J Neuroradiol 2006;33:105-14

11. Mounayer C, Hammami N, Piotin M, et al. Nidal embolization of brain arteriovenous malformations using Onyx in $\mathbf{9 4}$ patients. AJNR Am J Neuroradiol 2007;28:518-23

12. Lucas Cde P, Mounayer C, Spelle L, et al. Endoarterial management of dural arteriovenous malformations with isolated sinus using Onyx-18: technical case report. Neurosurgery 2007;61(5 suppl 2):E293-94, discussion E94

13. Nogueira RG, Dabus G, Rabinov JD, et al. Preliminary experience with Onyx embolization for the treatment of intracranial dural arteriovenous fistulas. AJNR Am J Neuroradiol 2008;29:91-97

14. Tahon F, Salkine F, Amsalem Y, et al. Dural arteriovenous fistula of the anterior fossa treated with the Onyx liquid embolic system and the Sonic microcatheter. Neuroradiology 2008;50:429-32

15. $\mathrm{Lv} \mathrm{X}, \mathrm{Li} \mathrm{Y}, \mathrm{Wu} \mathrm{Z}$. Endovascular treatment of anterior cranial fossa dural arteriovenous fistula. Neuroradiology 2008;50:433-37

16. Lv X, Li Y, Liu A, et al. Endovascular embolization of dural arteriovenous fistulas of the anterior cranial fossa: three case reports. Neurol Res 2008;30: $852-59$ 